\title{
Modelos de Self e Expressão Emocional em Bebês: Concepções de Mães e Outras Cuidadoras
}

\author{
Deise Maria L. Fernandes Mendes \\ Universidade do Estado do Rio de Janeiro \\ Rio de Janeiro, RJ, Brasil \\ Lilia Iêda Chaves Cavalcante \\ Universidade Federal do Pará \\ Pará, PA, Brasil
}

\begin{abstract}
RESUMO
Este estudo investigou metas de socialização que expressam expectativas e objetivos relacionados ao desenvolvimento emocional da criança por mães, avós, babás e cuidadoras de creche. As 120 participantes preencheram questionários e foram realizados testes estatísticos. Os resultados mostraram que entre as mães, $60 \%$ consideraram que crianças devem aprender a controlar emoções durante os três primeiros anos, enquanto $60 \%$ das outras cuidadoras, não. Todas acharam importante uma criança sorrir, e mais de $90 \%$ acreditavam que ao sorrir é mais importante ela manifestar suas emoções do que mostrar-se simpática com as pessoas. A alegria foi indicada como a emoção que mais cedo a criança manifesta. Foram encontradas diferenças estatisticamente significativas entre os grupos de participantes para o surgimento do nojo $F(1,117)=3,92$, surpresa $F(1,118)=6,78$, interesse $F(1,118)=4,30$, e aflição $F(1,117)=4,97$. Tais resultados são discutidos em termos da valorização da expressão emocional em crianças, associada a tendências para socialização segundo um modelo de self autônomo ou relacional.
\end{abstract}

Palavras-chave: Desenvolvimento emocional. Bebês. autonomia. Crenças (não-religiosas). Cuidadores.

\begin{abstract}
Models of Self and Emotional Expressions in Infants: Conceptions of Mothers and Other Caregivers

This study investigated socialization goals that express expectations and objectives related to the child's emotional development by mothers, grandmothers, nannies and childcare workers. The 120 participants filled out questionnaires and statistical tests were performed. The results showed that among mothers, $60 \%$ believed that children should learn to control emotions during the first three years, while $60 \%$ of the other caregivers, no. All of them found important a child smile, and over $90 \%$ believed that when smiling it's more important for a child to express her/his emotions than to be friendly. Joy was nominated as the emotion that earlier a child manifests. There were statistically significant differences between the profiles in relation to the emergence of disgust $F(1,117)=3.92$, surprise $F(1,118)=6.78$, interest $F(1,118)=4.30$, and distress $F(1,117)=4,97$. These results are discussed in terms of the appreciation of emotional expression in children, associated with trends for socialization according to a model of self autonomous or relational.
\end{abstract}

Keywords: Emotional development. Infants. Autonomy. Beliefs (nonreligious). Caregivers.

\section{RESUMEN}

\section{Modelos de Self e Expresión Emocional en los Bebés: Concepciones de las Madres y Otros Cuidadores}

Este estudio investigó las metas de socialización que expresan las expectativas y objetivos relacionados con el desarrollo emocional del niño por madres, abuelos, niñeras y cuidadores de guardería. Las 120 participantes completaron cuestionarios y se realizaron pruebas estadísticas. Los resultados muestraron que entre las madres, el $60 \%$ cree que los niños deben aprender a controlar las emociones durante los tres primeros años, mientras que el $60 \%$ de quienes lo atiendan, no. Todas encontram importante sonreír a un niño, y más del $90 \%$ cree que la sonrisa es más importante expresar sus emociones de mostrarse amable. La alegría fue descrito como la emoción que antes un niño se manifiesta. Hubo diferencias estadísticamente significativas entre los resultados obtenidos para el surgimiento de disgusto $F(1,117)=3,92$, sorpresa $F(1,118)=6,78$, intereses $F(1,118)=4,30$, y aflicción $F(1117)=4$, 97. Estos resultados se discuten en términos de la apreciación de la expresión emocional en los niños, asociada con las tendencias para socialización según un modelo de self autónomo o relacional.

Palabras clave: Desarrollo emocional. Lactante. Autonomia. Creencias (no religiosas). Cuidadores. 
A preocupação em investigar diferenças culturais em sistemas de crenças parentais está presente na produção atual acerca da parentalidade e tem trazido evidências e importante discussão a respeito do papel das concepções e metas de cuidadores e das práticas de cuidado no desenvolvimento infantil. Em geral, é assumido que, para o caso de sociedades urbanas ocidentais, cada criança é criada, principalmente por seu pai e/ou sua mãe, ficando exposta a um determinado conjunto de concepções e expectativas culturais a respeito de como se deve educar um filho(a) e de como ele(a) deverá se desenvolver, inclusive do ponto de vista emocional. Atualmente, no entanto, esta não é a situação observada em vários centros urbanos. Cada vez mais, com a globalização da economia e a forte entrada da mulher no mercado de trabalho, outros cuidadores são envolvidos nas atividades e cuidados diários da criança, desde que ainda é um bebê e, em razão disso, participam ativamente da constituição da sua trajetória de desenvolvimento.

As trocas afetivas que estabelecem com a criança e a forma com que lidam com as emoções - suas, dela e de outras pessoas que a cercam - tornam-se, pois, mais uma fonte significativa de referência e de aprendizagem. Por esse motivo, a relevância do estudo de metas de socialização, crenças e práticas de cuidado não apenas dos pais, mas também de outros cuidadores habituais, tem sido ressaltada em modelos conceituais voltados para a compreensão do processo de desenvolvimento emocional (Eisenberg, Spinrad e Cumberland, 1998; Keller e Otto, 2009). Estes trabalhos têm destacado o quanto valores e ideias parentais sobre as emoções afetam as escolhas de práticas e estratégias de socialização de emoção e, nesse sentido, o desenvolvimento emocional da criança. Sinalizam que o processo de socialização parece ser bidirecional, e que, assim como as práticas de cuidado repercutem na competência social e emocional das crianças, suas reações e comportamentos provavelmente têm efeitos diversos na forma como seus cuidadores agem com elas e as orientam (Mirabile, Scaramella, Sohr-Preston e Robison, 2009).

Uma ampla literatura sobre as interações sociais nos primeiros anos está disponível atualmente, mas apenas uma parte reduzida dela trata da expressão de emoções nas trocas afetivas entre bebês e cuidadores com a preocupação de investigar também a ontogenia das expressões emocionais em etapas iniciais (Mendes, Seidl-de-Moura e Siqueira, 2009). O contexto das trocas afetivas com os cuidadores, mas principalmente a mãe, tem sido considerado fundamental para as conquistas primárias essenciais dos bebês (Keller, 2007), sendo propício à manifestação de afeto positivo, à expressão de emoções diversas, e à regulação de suas interações com esses parceiros específicos.

$\mathrm{Na}$ medida em que a criança começa a perceber e antecipar os comportamentos emocionais do outro e atribuir-lhes significados, as interações afetivas tornam-se situações de promoção do desenvolvimento cognitivo, social e emocional saudável (Rochat, 2001). Entende-se aqui o desenvolvimento emocional não somente como expressão de programas genéticos ou produto de práticas de socialização, da experiência familiar e outras contingências ambientais (Martins e Vieira, 2010), mas precisamente como unidade indissociável de todos estes fatores (Mendes, 2009).

Como agentes primários de socialização, os pais e outros eventuais cuidadores ensinam às crianças como expressar suas emoções e percebê-las nas outras pessoas, enquanto a cultura fornece orientações que configuram as tendências voltadas para a criação dos filhos e padrões gerais de decodificação e exibição emocional influentes em cada contexto e época (Camras, Bakeman, Chen, Norris e Cain, 2006; Ekman, 2003; Keller e Otto, 2009). Assim, a visão de outros cuidadores que participam, no cotidiano, da criação das crianças merece também ser considerada.

A partir de seu modelo de sistemas parentais e dos resultados de estudos transculturais que desenvolveu com colaboradores (Keller, Borke, Yovsi, Lohaus e Jensen, 2005; Keller et al., 2006), Keller (2007) discute as metas de socialização com especial atenção para as diferentes trajetórias de desenvolvimento do self, com modelos que valorizam a autonomia e a relação ou interdependência. Os caminhos de desenvolvimento que se delineiam a partir dessas metas de socialização e das práticas a elas associadas podem favorecer o desenvolvimento de um self mais autônomo e independente, com foco nas características, necessidades e direitos individuais, conquistas e qualidades relacionadas ao autocontrole e habilidade para competir; ou o desenvolvimento de uma pessoa interdependente, que prioriza as relações sociais e consegue manter harmonia e equilíbrio nas trocas estabelecidas. Essas duas dimensões ou modelos, de autonomia e relação, estão presentes em todas as culturas, como necessidades humanas, porém em medidas que se diferenciam entre si, sendo essa composição de forças definidora das tipologias de self propostas pela autora, com consequente variação na forma como os indivíduos, e, portanto, os pais e cuidadores, lidam com as emoções.

Uma importante contribuição para se pensar essas dimensões do self vem de Kagitçibasi (2007), propondo um modelo que inclui a ênfase em ambas - autonomia e relação, a autonomia relacionada. Nessa concepção, 
o self é definido como autônomo em termos de agência, e relacional no sentido da proximidade interpessoal. Evidências para essa proposta são encontradas em famílias de classe média que vivem em contextos urbanos e apresentam alto nível educacional.

Estudos brasileiros que investigaram essas dimensões com base nas concepções teóricas de Keller (2007) e de Kagitçibasi (2007) têm concluído que, embora sejam identificadas trajetórias de socialização em que uma ou outra tende ser privilegiada, ambas são fundamentais na constituição do sujeito e importa estudar a dinâmica entre as duas (Seidl-de-Moura et al. 2008; Seidl-de-Moura et al. 2012). Um equilíbrio entre autonomia e relação tem sido considerado como ideal de um desenvolvimento saudável (Kagitçibasi, 2011). Desse modo, considera-se que essas investigações quando buscam revelar crenças e metas de cuidadores que estão na base dos modelos culturais centrados na autonomia e na relação, e suas implicações para o desenvolvimento, podem informar também sobre suas expectativas acerca de quando e como se dá a expressão das emoções em crianças, mas, principalmente, as estratégias de socialização que estes julgam capazes de definir o caminho para um desenvolvimento emocional mais saudável.

Especula-se nesse estudo que a articulação de crenças e metas de cuidadores, voltadas para autonomia e relação, e a ênfase dada a cada uma, com suas ideias e expectativas acerca da expressão de emoções em crianças compõe estratégias de socialização que definem diferentes caminhos do desenvolvimento emocional. Parece um aspecto crucial a ser investigado, porém, ainda hoje, uma lacuna na literatura científica.

Keller e Otto (2009) em seu estudo sobre o desenvolvimento inicial da regulação da emoção e o papel da cultura, argumentam que alguns dos processos relevantes para a socialização da emoção e metas parentais provavelmente se estendem a vários contextos, enquanto outros não. As autoras discutem seus resultados e concluem que em contexto agrário rural, em grupos sociais tradicionais que priorizam a interdependência, como os Nso de Camarões, o objetivo das estratégias de socialização é, desde cedo, o controle emocional, com ênfase na supressão da expressão de emoções negativas, como o choro. Por outro lado, em famílias de classe média, que vivem em contexto urbano ocidental, há valorização de tendências que apontam para uma maior independência do sujeito e para o individualismo, incluindo comportamentos que promovem autoexpressão e manifestação da emoção.

As mães de classe média de Berlim, entrevistadas por Keller e Otto (2009) mostraram clara valorização da expressão emocional nas crianças e incentivavam, sobretudo, o sorriso de seus bebês. Para essas mães, o cuidar das crianças deve ter como objetivo suscitar e manter emoções positivas, o que é desejado em contextos prototípicos urbanos ocidentais como este. Nesse sentido, entendem que ao olhar, vocalizar, mas principalmente sorrir para a mãe, a criança tende a se sentir cada vez mais confiante em relação ao ambiente, aumentando os comportamentos exploratórios e a disposição para a interação.

O crescente interesse de pesquisas científicas pelas manifestações emocionais no início da vida desde a década de 1980, segundo Mendes e Seidl-de-Moura (2009a), pode ser reflexo da importância atribuída por pesquisadores e pela sociedade em geral às habilidades do bebê humano para expressar e lidar com emoções e afetos. Em particular, o sorriso tem sido visto como um comportamento adaptativo e importante para o desenvolvimento humano por diferentes pesquisadores ao abordarem seus aspectos inatos, culturais e origens filogenéticas (Mendes e Seidl-de-Moura, 2009b).

A literatura da área indica observação de sorriso em bebês com algumas horas de nascidos, mas enquanto dormiam (Messinger et al., 2002), sendo, contudo, a partir do segundo mês de vida que são deflagradas alterações substanciais na sua capacidade de expressar emoções e desenvolver habilidades sociais, sendo nesse momento que surgem os sorrisos sociais (Mendes e Seidl-de-Moura, 2009a). Estes são deflagrados pelo contato com pessoas, em especial a face humana, que elicia essa forma específica de expressão emocional e permite o seu aprimoramento com o tempo. Nessa etapa do desenvolvimento, os bebês passam a reagir a comportamentos afetivos da mãe com sorrisos contingentes, que, em geral, tornam-se mais frequentes nos meses seguintes (Keller et al., 2005; Mendes et al., 2009).

É preciso notar, entretanto, que, como mostra a literatura mais recente (Baker, Fenning e Crnic, 2011; Mirabile et al., 2009), as etnoteorias e práticas influentes no cuidado infantil refletem modelos culturais vigentes nas sociedades em que vive a criança e seus diferentes cuidadores. É ressaltado, ainda, que tais etnoteorias e práticas de cuidado têm implicações para a competência emocional em formação, assim como para uma determinada concepção de self. Entre outros autores, Chan, Bowes e Wyver (2009) e Chan (2011) mostram que mães chinesas de Hong Kong tendiam a uma concepção de self predominantemente interdependente e valorizavam mais em seus filhos uma competência emocional relacional. Embora, em seu conjunto, as mães tenham valorizado tanto a competência emocional relacional quanto a 
individualista como metas de desenvolvimento dos filhos, consideravam a primeira mais importante do que a outra.

Segundo Chan (2011), a competência emocional valorizada por quem tem uma concepção de self independente inclui compreender as emoções, expressá-las de modo natural, especialmente as voltadas para $o e u$, e apresentar uma competência emocional independente ou individualista. De modo oposto, a noção de self interdependente enfatiza a importância de se aprender a regular as emoções, especialmente as centradas no $\mathrm{eu}$, e incentiva as voltadas para o outro, priorizando uma competência emocional relacional. Em estudo de Matsumoto, Willingham e Olide (2009), fica claro que atletas de culturas individualistas, que viviam em meio urbano, expressaram mais suas emoções do que os provenientes de culturas coletivistas, que tenderam a "mascarar" as suas. Sobre a questão, Markus e Kitayama (1991) já haviam feito afirmação semelhante ao mostrarem que o modelo de self reflete-se nos diversos domínios da vida, incluindo as emoções. Consequentemente, a concepção de self dos pais, e o grau em que valorizam um self mais autônomo, mais relacional, ou uma composição equilíbrada destas tendências, afetariam suas metas de socialização relacionadas à emoção.

Keller e Otto (2009) analisaram as expectativas por parte de mães de dois contextos prototípicos, Nso e Berlim, quanto ao início da manifestação de certas emoções por suas crianças. Seus resultados indicaram que as mães alemãs têm expectativa de ver as crianças expressarem suas emoções mais precocemente do que as mães Nso, com exceção de duas das emoções investigadas: vergonha e culpa. Para ambas, as mães de Camarões esperavam vê-las manifestadas em idades em torno de dez meses antes do que as mães de Berlim. Este resultado considera a diversidade de construções culturais a respeito das ideias de self e relação, e que essas são emoções autorreferenciadas que regulam as relações sociais. Esta é uma preocupação característica de contextos prototípicos como o de Camarões (Keller, 2007) em que predomina valorização da interdependência e não da autonomia.

Lewis (2010) propõe um modelo da emergência de emoções diversas nos três primeiros anos de vida, embora problematize a questão da definição de marcadores apropriados para emoção em crianças pequenas. Enquanto a linguagem é ausente ou limitada, o estudo da experiência emocional é difícil. Contrariamente a outras visões que apontam um conjunto de emoções básicas (Ekman, 1992), biologicamente determinadas, e presentes desde o nascimento, o autor assume que a criança ao nascer mostra uma vida emocional bipolar.
O bebê, nessa perspectiva, manifesta o desconforto geral marcado pelo choro e irritabilidade, o prazer marcado pela saciedade, atenção e responsividade ao ambiente. Aos três meses, indica que as crianças já mostram interesse, alegria, tristeza e nojo, e exibem essas expressões em contextos apropriados.

Outros autores também têm se dedicado à observação das competências emocionais no primeiro ano de vida e tecem considerações sobre a idade em que é esperado que a criança se torne capaz de expressar emoções. A raiva tem sido relatada como emergindo entre quatro e seis meses (Stenberg, Campos e Emde, 1983), embora para Lewis (2010) seja observada por volta dos dois meses. Já o medo, se não entendido como inato, parece ocorrer desde as etapas iniciais a depender do seu tipo e estímulo promotor (LoBue, 2013). Por sua vez, a surpresa para Lewis (2010) aparece nos primeiros seis meses de vida, mas segundo Reissland e Shepherd (2002) é claramente expressa apenas um pouco mais tarde. Contudo, para as perspectivas evolucionárias, as emoções são universais e inatas (Izard, 1997), compreendendo além do medo, a alegria, tristeza, raiva, nojo, interesse, aflição e surpresa.

De acordo com Lewis (2010), seja quando a emoção é associada a estados e padrões de ações ou a experiências desencadeadas por eliciadores ambientais, em qualquer das definições pode-se afirmar que o desenvolvimento da capacidade de expressá-las e da competência para regulá-las tem sido visto como um processo que requer níveis mais elaborados de processos cognitivos. Segundo o autor, por volta da segunda metade do segundo ano de vida é que se assiste à emergência de uma nova capacidade cognitiva no processo de desenvolvimento infantil, com a manifestação pela criança de uma nova classe de emoções que incluem constrangimento, empatia e inveja.

Para ser mais sistemático, Lewis (2010) estabelece que um segundo marco cognitivo ocorre entre os dois e três anos de idade, tornando a criança gradativamente capaz de avaliar seu comportamento em relação a um padrão. Estas emoções incluem orgulho, vergonha e culpa, entre outras. Em torno dos três anos a vida emocional de uma criança torna-se, assim, bastante diferenciada, e ela passa a apresentar um sistema de emoções complexo e elaborado.

Em razão do exposto, admite-se hoje que, com a idade, variam não só o tipo e a forma de expressão das emoções humanas, mas também o nível de influência das etnoteorias parentais acerca do desenvolvimento emocional e as metas de socialização dos seus diferentes cuidadores (pais, avós, babás, cuidadores de creche, por exemplo). Nesse sentido, presume-se que as 
diferenças culturais e de contextos sociodemográficos devem exercer impacto nas metas e expectativas de pais e demais cuidadores, e ter efeito sobre as expressões emocionais desde aos primeiros anos de vida. Entende-se ainda que as práticas de socialização da emoção que representam as expectativas dos pais quanto ao desenvolvimento emocional dos filhos variem em função da cultura, assim como de outros elementos das etnoteorias parentais (Chan, 2011; Keller e Otto, 2009), embora sejam idiossincráticas e não facilmente articuladas pelos pais ou pela criança (Dunsmore, Her, Halberstadt e Perez-Rivera, 2009).

Pelo exposto, conclui-se que examinar as metas parentais e expectativas de outros cuidadores sobre as emoções pode prover um caminho importante para compreender o ambiente familiar de socialização que influencia o desenvolvimento da criança, assim como o que a torna mais capaz de reconhecer, expressar e lidar com as diferentes emoções, sendo este um exemplo da abrangência social e científica desse tipo de investigação.

Como um estudo representativo da pesquisa que reconhece a influência das metas de socialização de pais e outros cuidadores sobre o desenvolvimento infantil, Greenfield, Flores, Davis e Salinkham (2008) compararam mães americanas (empregadoras) e babás imigrantes latinas e americanas (empregadas) em suas crenças sobre práticas e metas de desenvolvimento. As autoras hipotetizaram diferenças nesses aspectos entre as mães americanas e as babás, e a influência de variáveis sociodemográficas nessas orientações culturais, independentemente da origem étnica.

As participantes foram entrevistadas e suas respostas tratadas a partir de um método de análise do discurso. Foram encontradas diferenças relacionadas a dois caminhos de desenvolvimento, um mais coletivista e voltado para interdependência e responsabilidade social, e outro mais individualista e que aponta para o desenvolvimento cognitivo e independência. Para as autoras, as hipóteses foram confirmadas, uma vez que entendem que os valores culturais se desenvolvem como uma adaptação às condições sociodemográficas, e que as diferenças encontradas entre as participantes podem ser atribuídas à educação formal.

Conhecer crenças e expectativas que orientam as metas, estratégias e práticas envolvidas na socialização das emoções não somente as dos pais, mas também dos demais cuidadores, parece ser uma tarefa fundamental à compreensão do desenvolvimento emocional na contemporaneidade. Pretende-se, neste estudo, investigar, pois, as possíveis conexões entre as concepções dessas diferentes categorias de cuidadores em torno da manifestação das emoções nos primeiros anos de vida e a valorização que conferem às metas de desenvolvimento mais voltadas ao desenvolvimento da autonomia ou da interdependência.

\section{MÉTODO}

\section{Participantes}

Participaram deste estudo quatro categorias de cuidadoras na cidade do Rio de Janeiro: mães, avós, babás e cuidadoras de creche. As 120 participantes foram assim organizadas: 20 duplas de mães e avós; 20 duplas de mães e babás; e mais 20 de mães e cuidadoras de creche. As mães tinham filhos de até um ano de idade. Foi utilizada uma amostragem por conveniência, em que as duplas/díades foram indicadas por membros do grupo de pesquisa Interação Social e Desenvolvimento (cadastrado no diretório de grupos de pesquisa do $\mathrm{CNPq}$ - GrPesq4), por participantes colaboradores desta pesquisa, familiares e amigos, além de serem selecionadas em creches da cidade do Rio de Janeiro. As mães tinham bebês de ambos os sexos, $43,3 \%$ meninos e $56,7 \%$ meninas, com idade média de 7,83 meses $(D P=3,12)$. As idades médias das participantes foram de 31,9 anos para as mães $(D P=4,55), 58,75(D P=5,48)$ para as avós, $41,5(D P=12,28)$ para as babás e $35,5(D P=9,81)$ para as cuidadoras de creche. Seu nível de escolaridade declarado dividiu-se do seguinte modo: (a) ensino médio incompleto - 5\% das mães, $35 \%$ das avós, $70 \%$ das babás, e $5 \%$ das cuidadoras de creche; (b) ensino médio completo - 3\% das mães, $15 \%$ das avós, $25 \%$ das babás, e $50 \%$ das cuidadoras de creche; e (c) nível superior ou acima - $86,7 \%$ das mães, $50 \%$ das avós, $5 \%$ das babás, e $45 \%$ das cuidadoras de creche.

\section{Instrumentos}

Foram utilizados instrumentos autoexplicativos e de fácil preenchimento: (1) Escala de avaliação da autonomia e interdependência (já adaptada e validada para uso em população brasileira por meio de pesquisa coordenada pela Prof ${ }^{a}$ Maria Lucia Seidl-de-Moura); este instrumento foi adaptado a partir das escalas de autonomia, interdependência e autonomia relacionada de Kagitçibasi (2007), sendo composto de 27 afirmativas para as quais o participante deve indicar o grau em que concorda com ela, podendo optar desde nem um pouco até completamente (escala Likert de 5 pontos); (2) Questionário sobre Avaliação de Emoções, um questionário estruturado, composto de quatro perguntas dirigidas aos cuidadoras de crianças, indagando se consideram que a criança deve aprender a controlar suas emoções nos primeiros três anos de vida, se é importante ela sorrir, a partir de que idade e por 
que isso pode ser importante, e o período da infância em que pensam que elas começam a expressar as oito emoções consideradas neste estudo (alegria, tristeza, medo, raiva, nojo, surpresa, interesse e aflição); e (3) Informações sociodemográficas, um questionário com questões sobre grau de escolaridade, idade, atividade profissional e outras.

\section{Procedimentos}

As participantes (mães e avós, babás e cuidadoras de creche) foram entrevistadas individualmente em local, dia e horário de sua conveniência. Nas entrevistas, foi aplicada a Escala de Avaliação de Autonomia e Interdependência, e preenchidos os questionários sobre emoções e dados sociodemográficos. As escalas receberam escores. Os resultados obtidos no instrumento sobre emoções foram cruzados com os valores atribuídos às diferentes dimensões do self aqui tratadas. As variáveis idade, nível educacional e sexo do bebê foram consideradas na comparação dos resultados dos diferentes tipos de cuidadoras, e de cada subgrupo (mãe-avó, mãe-babá, mãe-cuidadora de creche).

\section{Procedimentos éticos}

Este estudo foi aprovado pelo Comitê de Ética da Universidade do Estado do Rio de Janeiro (Protocolo 010.3.2010), tendo sido o termo de consentimento previamente apresentado às participantes e assinado por elas.

\section{Análise de dados}

Foram calculados os escores de autonomia, interdependência e autonomia relacionada para cada participante. Em seguida, foi realizado teste t pareado para analisar diferenças de médias entre os escores de autonomia, interdependência e autonomia relacionada a cada perfil de cuidadora, além de GLM multivariado para testar diferenças entre grupos de cuidadoras em função do seu nível de escolaridade e do sexo da criança. Também foi empregado GLM para avaliar o impacto de dois fatores nos escores de autonomia, interdependência e autonomia relacionada das participantes, que são: (1) a opinião das mães e demais cuidadoras sobre a necessidade de a criança aprender a controlar suas emoções até os três anos de idade, e (2) o motivo pelo qual consideram que é importante a criança sorrir.

\section{RESULTADOS E DISCUSSÃO}

O teste realizado para verificar diferenças das médias dos escores referentes à autonomia, interdependência e autonomia relacionada, das mães e demais cuidadoras, indicou valores significativamente maiores para esta última categoria (ver Tabela 1). Nas análises dos escores das demais cuidadoras obteve-se este mesmo resultado para avós e babás. Entretanto, no caso das cuidadoras de creche, a diferença das médias que representam os escores de autonomia e autonomia relacionada foi significativa, mas o mesmo resultado não foi observado entre os escores de interdependência e autonomia relacionada, indicando uma equivalência na ênfase atribuída por elas a estes dois modelos considerados pela pesquisa.

Foi verificado se há relação dos escores com a idade das cuidadoras, sendo isso observado apenas no caso dos escores das mães no que se refere à categoria autonomia relacional $(\mathrm{r}=0,52 ; p<0,01)$. Em relação ao efeito de escolaridade sobre os escores nas três escalas foi encontrado resultado significativo para o escore de autonomia relacional somente das mães $F(2,57)=11,650 ; p<0,05$. Este resultado aponta a influência de tais variáveis sociodemográficas nos escores das mães, mas não das outras cuidadoras, e naquele que se refere à autonomia relacionada, que obteve médias significativamente mais altas para a maior parte das participantes.

TABELA 1

Diferença de médias para os escores de autonomia, interdependência e autonomia-relacionada

\begin{tabular}{|c|c|c|c|c|c|c|}
\hline \multirow{2}{*}{ Grupos } & \multicolumn{3}{|c|}{ Mães } & \multicolumn{3}{|c|}{ Outras cuidadoras } \\
\hline & Média & $D P$ & $t$ & Média & $D P$ & $t$ \\
\hline Par 1 Escore de autonomia & 29,35 & 5,14 & & 28,90 & 5,81 & \\
\hline Escore de interdependência & 32,82 & 5,03 & $-2,91 *$ & 32,48 & 4,35 & $-3,35^{*}$ \\
\hline Par 2 Escore de autonomia & 29,35 & 5,14 & & 28,90 & 5,81 & \\
\hline Escore de autonomia-relacionada & 40,92 & 4,55 & $-13,82^{*}$ & 38,15 & 9,36 & $-7,25^{*}$ \\
\hline Par 3 Escore de interdependência & 32,82 & 5,03 & & 32,48 & 4,38 & \\
\hline Escore de autonomia-relacionada & 40,92 & 4,55 & $-9,99 *$ & 38,15 & 9,36 & $-4,45 *$ \\
\hline
\end{tabular}


De modo geral, pode-se considerar que este conjunto de participantes tende a valorizar tanto a autonomia quanto a interdependência nas crianças. Tal posicionamento mostra ser esperado que as crianças desenvolvam um senso de agência e independência em que características, necessidades e desejos individuais estejam em foco, mas que também valorizem aspectos relacionais como uma ligação mais próxima com as outras pessoas com quem convivem (Keller, 2007). Implica ainda a expectativa de que sejam capazes de interagir com parceiros sociais de forma a buscar a harmonia, e acatar respeitosamente as regras sociais (Kagitçibasi, 2007; Keller, 2007).

No que concerne aos dados relativos às convicções das cuidadoras acerca da expressão de emoções na infância, calculou-se as idades médias (em meses) em que as crianças começam a apresentar esse tipo de manifestação. No que se refere à capacidade da criança expressar determinadas emoções, mães e outras cuidadoras informaram médias de idade mais baixas para a alegria (mães, $M=3,3, D P=6,26$; outras cuidadoras, $M=4,4, D P=7,88)$, seguida da tristeza (mães, $M=7,9, D P=10,65$; outras cuidadoras, $M=12,2, D P=16,52$ ), do interesse (mães, $M=9,1$, $D P=17,26$; outras cuidadoras, $M=16,4, D P=21,17)$, e do medo (mães, $M=9,2, D P=13,16$; outras cuidadoras, $M=12,5, D P=18,60)$. Idades posteriores foram indicadas para a surpresa (mães, $M=12,2, D P=14,70$; outras cuidadoras, $M=23,6, D P=30,60$ ), aflição (mães, $M=15,1, D P=23,79$; outras cuidadoras, $M=29,1$, $D P=42,04$ ), raiva (mães, $M=15,8, D P=24,20$; outras cuidadoras, $M=25,0, D P=31,54)$, e as mais elevadas para o nojo (mães, $M=18,4, D P=15,92$; outras cuidadoras, $M=28,3, D P=34,96)$.

Se contrastadas com o que a literatura apresenta, as cuidadoras entrevistadas se distanciam de uma perspectiva evolucionária, em que essas emoções são vistas como presentes nos seres humanos já no início da vida (Izard, 1997). Por outro lado, também se afastam das concepções de autores que pressupõem um processo de desenvolvimento para essas capacidades expressivas, como Lewis (2010), na medida em que suas expectativas para todas as emoções estão além da idade em que este autor preconiza sua emergência. No caso do nojo e da raiva, em especial, acreditam se tratar de emoções que surgem bem depois da fase associada por este autor ao início da observação dessas experiências emocionais. Note-se, entretanto, que a alegria, em geral associada à exibição de sorrisos, está relacionada pelas cuidadoras a um período da ontogênese por volta do qual emerge o chamado sorriso social (Mendes e Seidl-de-Moura, 2009a), denotando a associação dessa expectativa com a observação de expressões faciais no bebê que indicam reação ou resposta a algum estímulo social, como ocorre nas interações com as pessoas que cuidam dele. O nojo e a raiva, ao contrário, são emoções menos esperadas nessa fase da vida, como se não fossem próprias de bebês com menos de um ano.

Comparando-se as idades indicadas pelas mães e demais participantes para o início da manifestação das emoções apresentadas no questionário, verificou-se que, para todas elas, as médias de idades atribuídas pelas mães foram inferiores às das demais cuidadoras. No entanto, uma diferença estatisticamente significativa entre esses dois grandes grupos de participantes foi encontrada apenas no caso do nojo $(F(1,117)=3,923$; $p<0,05)$, da surpresa $(F(1,118)=6,782 ; p<0,05)$, do interesse $(F(1,118)=4,304 ; p<0,05)$, e da aflição $(F(1,117)=4,973 ; p<0,05)$. Se comparados apenas os diferentes grupos de mães (em função do perfil de cuidadora com quem compartilham o cuidado do bebê) não foi encontrada diferença estatisticamente significativa. Mas, se comparadas entre si apenas as demais cuidadoras, ou seja, avós, babás e cuidadoras de creche, diferença significativa aparece para o interesse $(F(1,58)=7,197 ; p<0,05)$ e aflição $(F(1,58)=5,254$; $p<0,05)$.

Não foi identificada na literatura evidência que sustente ou contradiga esse resultado, mas observou-se diferença significativa nas médias de idade dos grupos de participantes, sendo que as mães tinham idade média bem inferior à das demais cuidadoras $(\mathrm{t}(119)=7,054, p<0,05)$. Verificou-se também haver diferença significativa entre os grupos quanto ao nível de escolaridade, com frequência bem maior de mães $(86,7 \%)$ em relação às demais cuidadoras, com grau de escolaridade acima do nível superior. Conjectura-se que fatores sociodemográficos estejam associados a essa diferença na atribuição de idade às emoções.

Foi testado se o sexo da criança pode ser fator de influência para a idade informada pela mãe e pelas outras cuidadoras, para cada emoção analisada, não tendo sido encontrado resultado significativo para nenhuma das emoções. Verificou-se, ainda, se o nível de escolaridade das cuidadoras seria responsável pela diferença observada nessas respostas, e obteve-se resultado significativo no caso das mães para a surpresa $(F(1,57)=6,587 ; p<0,05)$, interesse $(F(1,57)=10,727$; $p<0,05)$, e aflição $(F(1,57)=3,966 ; p<0,05)$, e no caso das outras cuidadoras para surpresa $(F(1,57)=6,404$; $p<0,05)$ e aflição $(F(1,57)=7,629 ; p<0,05)$, o que parece reforçar a especulação feita a respeito do possível impacto do grau de escolaridade da cuidadora nesse tipo de crença. Por outro lado, o sexo do bebê 
não parece influenciar a expectativa de manifestação emocional por parte de mães e cuidadoras.

Para a pergunta "As crianças devem aprender a controlar emoções nos três primeiros anos de vida", $60 \%$ das mães disseram que sim, e $60 \%$ das demais cuidadoras responderam que não. No entanto, essa divergência de opiniões não se traduziu em uma predominância estatisticamente significativa de uma das respostas. No conjunto de mães, responderam positivamente à pergunta $45 \%$ das que deixavam seus filhos com as avós, 55\% com babás, e 80\% em creches. Entre as demais cuidadoras, averiguou-se que $40 \%$ das avós, $45 \%$ das babás e apenas $25 \%$ das cuidadoras de creche responderam que sim à mesma pergunta. Não foi encontrado resultado significativo, para nenhum dos perfis de cuidadoras, ao ser testado se a resposta para a pergunta a respeito do controle das emoções poderia ser um fator de diferença para os escores de autonomia, interdependência e autonomia relacionada.

Chama atenção a discrepância entre os percentuais de respostas positivas no grupo de mães e no de outras cuidadoras, sinalizando uma maior atenção das primeiras à necessidade do controle emocional por parte dos bebês, especialmente, para aquelas que optaram por uma creche para cuidar de seus filhos quando elas mesmas não o estão fazendo. Talvez a necessidade de convivência com um conjunto diverso de adultos e também outras crianças na creche, faça com que essas mães almejem um maior controle emocional de seus bebês, como forma de favorecer o cuidado e a comunicação com eles. No entanto, esse tipo de expectativa não é compartilhado pela maioria das cuidadoras de creche. Neste aspecto, ficou evidenciado maior acordo das mães com avós e babás, e certo desacordo com as cuidadoras de creche.

As idades informadas pelas mães e demais cuidadoras para o que consideravam ser aquela a partir da qual é importante os bebês humanos sorrirem, tiveram média em torno de dois meses. A média das mães ficou pouco acima desta, e a das outras participantes, mais próxima dos três meses. Estratificando-se os resultados por perfil, observou-se que as avós indicaram, em média, uma idade mais cedo, de pouco mais de dois meses, enquanto para as babás e cuidadoras de creche a média ficou em torno de três meses. Dentre as mães, as que apresentaram a média mais alta foram as que têm uma babá $(\mathrm{M}=2,45, D P=1,60)$, seguidas pelas que dividem os cuidados com a avó $(\mathrm{M}=2,10, D P=1,55)$, e com a creche $(\mathrm{M}=1,90, D P=1,51)$. Estatisticamente, não foi encontrada diferença significativa entre os diferentes grupos de cuidadoras. Nesse aspecto, as crenças das participantes vão ao encontro do que a literatura (Messinget et al., 2002) refere como sendo a idade média em que, normalmente, emerge o sorriso social - o segundo mês de vida.

Quando indagadas quanto à importância de a criança sorrir, todas as participantes reconheceram seu valor. Desse conjunto, $98 \%$ das mães e $87 \%$ das demais cuidadoras indicaram como razão principal para que isso aconteça, a importância de a criança manifestar suas emoções e sentimentos, em detrimento da disposição para ser simpática e agradável com as outras pessoas. Tais resultados contrastam a primeira opção, mais voltada para a priorização de um self agente, com desejos e ações centradas no indivíduo, com a outra, que valoriza aspectos voltados para a relação com o outro (Chan, 2011; Keller e Otto, 2009). Ou seja, esse grupo de participantes considera importante manifestar emoções e sentimentos pelo sorriso, mas as mães pensam que emoções em geral precisam ser controladas. Uma vez mais se considera que diferenças no perfil sociodemográfico das participantes podem estar influenciando este resultado.

Ao se analisar, separadamente, as respostas apuradas por perfil de cuidadora, constatou-se que todas as mães que deixavam seus filhos com as avós e todas as que tinham babá pensavam ser importante a criança sorrir para manifestar suas emoções e sentimentos, enquanto $95 \%$ das mães que deixavam seus bebês na creche tinham essa convicção. Essa mesma ideia a respeito da expressão do sorriso foi compartilhada por 95\% das cuidadoras de creche, $90 \%$ das avós, e $75 \%$ das babás. Esses percentuais sugerem que de todas as cuidadoras, as babás são as que parecem valorizar mais os aspectos da relação com o outro na expressão emocional, e não foi encontrada evidência desse tipo na revisão da literatura.

Neste estudo, foi verificado ainda se a opinião das participantes quanto à razão pela qual é importante a criança sorrir foi fator de influência para os seus escores de autonomia, interdependência e autonomia relacionada. Não foi obtido resultado significativo para as outras cuidadoras, mas entre as mães que mantinham seus bebês em creche foi encontrado resultado significativo para o escore de autonomia relacionada. Para os outros perfis de cuidadoras, se analisados individualmente, não houve diferença significativa. Assim, essa convicção a respeito da razão pela qual consideram ser importante a criança sorrir, no grupo das outras cuidadoras não esteve associada de forma significativa à ideia de que ela, por isso, possa se tornar mais autônoma ou mais relacional. Já para as mães que mantêm seus bebês em creche, a função atribuída ao sorriso impactou sua priorização da autonomia relacionada na trajetória de desenvolvimento do self. 


\section{CONSIDERAÇÕES FINAIS}

Considerando-se a relevância do estudo de metas de socialização, crenças e práticas de cuidado e de estratégias de socialização de emoção para a compreensão do desenvolvimento emocional infantil, o objetivo dessa investigação parece justificado, especialmente por não terem sido identificadas na literatura investigações com o mesmo interesse. Algumas são voltadas especificamente para autonomia e interdependência, outras tratam crenças parentais a respeito do desenvolvimento, porém sem levar em conta estas dimensões, ou até abordam aspectos diversos do desenvolvimento emocional, mas sem estabelecer uma articulação desses domínios. Acrescente-se a esse recorte de interesses a preocupação em levar em conta variáveis sociodemográficas que parecem ter impacto sobre as metas e expectativas de pais e outros cuidadores, como argumentam Greenfield et al. (2008).

A valorização tanto do modelo de desenvolvimento que privilegia a autonomia quanto a interdependência nas crianças esteve presente nos diferentes perfis estudados, corroborando investigações anteriores no Brasil. Pode-se pensar, assim, que mães e outras cuidadoras neste estudo, em contexto urbano do Rio de Janeiro, privilegiam ambas as características em uma trajetória de desenvolvimento desejável. O impacto da idade e nível de educação formal nos escores das mães para autonomia relacionada pode reforçar o argumento de Greenfield et al. (2008) de que os valores da cultura se desenvolvem como uma adaptação a condições sociodemográficas, em particular a escolaridade.

Mães e cuidadoras em geral apresentam uma noção sobre o momento em que emergem as emoções na vida da criança que contrasta com a presente em diversas perspectivas teóricas da área e com os achados de diferentes pesquisas sobre essa questão. Bem mais tardiamente do que as evidências apontam, são vistas pelas participantes todas as emoções surgindo, à exceção da alegria. Talvez esta, por ter uma sinalização forte e esperada socialmente, que é o sorriso, e todas as outras não. Isso pode ser motivo para que não se admita a existência em bebês da capacidade de terem certas experiências emocionais e externá-las. Algumas, inclusive, podem não ser algo desejado para um bebê experimentar e exibir, como a raiva e o nojo.

Estudos futuros são necessários para o avanço na investigação de muitas questões aqui apontadas, como a diferença significativa entre mães e cuidadoras quanto às idades em que as crianças começam a expressar emoções. Particularmente, quanto ao sorriso, como discutido, é não só uma expectativa clara por parte das cuidadoras e mães, como seu surgimento é associado a um momento da ontogênese bem próximo daquele que a literatura e evidências de pesquisas mostram. Um aspecto relevante a esse respeito é a associação dessa manifestação de alegria a necessidades e características do indivíduo, e não tanto a uma forma de manter harmonia e ligação com as outras pessoas. É ilustrativo da valorização pelas participantes de tendências de self autônomo. De todas as cuidadoras, as babás foram as que valorizaram mais os aspectos da relação interpessoal na expressão emocional, o que talvez se deva ao fato de viverem o cotidiano de grupos de crianças interagindo.

Confirmou-se o efeito de variáveis sociodemográficas, nesse caso o nível de escolaridade, nas crenças e expectativas quanto à idade em que crianças são capazes de manifestação emocional. Ainda são necessários novos estudos para que melhor se compreenda as razões que levam mães a estarem mais atentas e preocupadas do que outras cuidadoras, com a importância de um controle emocional por parte dos bebês, especialmente, aquelas que têm seus filhos, parte do dia, em uma creche.

Muitas possibilidades investigativas parecem ter aflorado dos resultados obtidos. Algumas limitações importantes, como uma grande concentração de mães em nível de escolaridade muito alto, e pouco representativo da realidade da maioria das mães brasileiras, merecem ser tratadas com novos recortes de participantes. Como contribuição para o avanço na área, acredita-se ter sido obtido um conjunto de evidências ainda não disponíveis em estudos sobre crenças de cuidadores ou acerca do desenvolvimento emocional, particularmente em contextos brasileiros.

\section{REFERÊNCIAS}

Baker, J. K., Fenning, R. M., \& Crnic, K. (2011). Emotion socialization by mothers and fathers: coherence among behaviors and associations with parent attitudes and children's social competence. Social Development, 20(2), 103-114. DOI: 10.1111/j.1467-9507.2010.00585.x

Camras, L. A., Bakeman, R., Chen, Y., Norris. K., \& Cain, T. R. (2006). Culture, ethnicity, and children's facial expressions: a study of european american, mainland chinese, chinese american, and adopted chinese girls. American Psychological Association, 6(1), 103-114. DOI: 10.1037/1528-3542.6.1.103

Chan, S. M. (2011). Mothers' construal of self and emotion socialisation goals. Early Education \& Development, 181(5), 613-624. DOI: 10.1080/03004431003671820

Chan, S. M., Bowes J., \& Wyver, S. (2009). Parenting Style as a Context for Emotion Socialization. Early Education \& Development, 20(4), 631-656. DOI: 10.1080/10409280802541973

Dunsmore, J. C., Her, P., Halberstadt, A. G., Perez-Rivera, M. B. (2009). Parents' beliefs about emotions and children's recognition of parents' emotions. Journal of Nonverbal Behavior, 33(2), 121-140. 
Eisenberg, N. Spinrad, A., \& Cumberland, T. L. (1998). Parental Socialization of Emotion. Psychologycal Inquiry, 9(4), 241-273.

Ekman, P. (1992). An argument for basic emotions. Cognition and Emotion, 6(3-4), 169-200.

Ekman, P. (2003). Emotions revealed: recognizing faces and feelings to improve communication and emotional life. NY: Times Books.

Greenfield, P. M.; Flores, A.; Davis, H., \& Salimkhan, G. (2008). What happens when parents and nannies come from different cultures? Comparing the caregiving belief systems of nannies and their employers. Journal of Applied Developmental Psychology, 29(4), 326-336.

Izard, C. E. (1997). Emotions and facial expressions: A perspective from differential emotions theory. In J. A. Russell, \& J. M. Fernandez-Dols (Eds.). The psychology of facial expression (pp. 57-77). New York: Cambridge University Press.

Kagitçibasi, C. (2007). Family, Self, and Human Development Across Cultures. Londres: Lawrence Erlbaum Associates Publishers.

Kagitçibasi, C. (2011). Sociocultural Change and Integrative Syntheses in Human Development: Autonomous-Related Self and Social-Cognitive Competence. Child Development Perspectives, 6(1), 5-11. DOI: 10.1111/j.1750-8606.2011.00208.x

Keller, H. (2007). Cultures of infancy. Mahwah, NJ: Lawrence Erlbaum.

Keller, H., Lamm, B., Abels, M., Yovsi, R., Borke, J., Jensen, H. et al. (2006). Cultural Models, Socialization Goals, and Parenting Ethnotheories: A Multicultural Analysis. Journal of Cross-Cultural Psychology, 37(2), 155-172. DOI: 10.1177/ 0022022105284494

Keller, H., Borke, J., Yovsi, R., Lohaus, A., H. Jensen (2005). Cultural orientations and historical changes as predictors of parenting behavior. International Journal of Behavioral Development, 29, 229-237. DOI: 10.1177/01650250544000017

Keller, H., Otto, H. (2009). The Cultural Socialization of Emotion Regulation During Infancy. Journal of Cross-Cultural Psychology, 40(6), 996-1011. DOI: 10.1177/0022022109348576

Lewis, M. (2010). The Emergence of Human Emotions. In M. Lewis, J. M. Haviland-Jones \& L. F. Barrett (Eds.) Handbook of Emotions (3 ${ }^{\text {nd }}$ ed.) (pp. 304-319). New York: The Guilford Publications.

LoBue, V. (2013). What Are We So Afraid of? How Early Attention Shapes Our Most Common Fears. Child Development Perspectives, 7(1), 38-42. DOI: 10.1177/0022022109348576

Markus, H. R., \& Kitayama, S. (1991). Culture and the self: Implications for cognition, emotion, and motivation. Psychological Review, 98, 224-253.

Martins, G. D. F., \& Vieira, M. (2010). Desenvolvimento humano e cultura: integração entre filogênese, ontogênese e contexto sociocultural. Estudos de Psicologia, 15(1), 63-70.

Matsumoto, D., Willingham, B., \& Olide, A. (2009). Sequential dynamics of culturally-moderated facial expressions of emotion. Psychological Science, 20(10), 1269-1274.
Mendes, D. M. L. F. (2009). As expressões emocionais e o desenvolvimento inicial. In M. L. Seidl-de-Moura, D. M. L. F. Mendes \& L. F. Pessôa (Orgs.). Interação Social e Desenvolvimento (pp. 71-85). Campinas: Editora CRV.

Mendes, D. M. L. F., Seidl-de-Moura, M. L., \& Siqueira, J. O. (2009). The ontogenesis of smiling and its association with mothers' affective behaviors: a longitudinal data. Infant Behavior and Development, 32(4), 445-453. DOI:10.1016/ j.infbeh.2009.07.004

Mendes, D. M. L. F., \& Seidl-de-Moura (2009a). Expressões faciais de emoção em bebês: importância e evidências. Estudos e Pesquisas em Psicologia, 2, 307-327.

Mendes, D. M. L. F., \& Seidl-de-Moura (2009b). O sorriso humano: aspectos universais, inatos e os determinantes culturais. Arquivos Brasileiros de Psicologia, 61(1), 109-120.

Messinger, D., Dondi, M., Nelson-Goens, G. C., Beghi, A., Fogel, A., \& Simion, F. (2002). How sleeping neonates smile. Developmental Science, 5, 48-54.

Mirabile, S. P., Scaramella, L. V., R., Sohr-Preston, S. L., Robison, S. D. (2008). Mothers' Socialization of Emotion Regulation: The Moderating Role of Children's Negative Emotional Reactivity. Child Youth Care Forum, 38, 19-37. DOI: 10.1007/s10566-0089063-5

Reissland, N. \& Shepherd, J. (2002). Gaze direction and maternal pitch in surprise-eliciting situations. Infant Behavior \& Development, 24, 408-417.

Seidl-de-Moura, M. L., Lordelo, E., Vieira, M. L., Piccinnini, C. A., Siqueira, J. e O., Magalhães, C. M. C. et al. (2008). Brazilian mothers' socialization goals: intracultural differences in seven cities. International Journal of Behavioral Development, 32(6), 465-472.

Seidl-de-Moura, M. L., Bandeira, T. T., de Marca, R. G. da C., Pessôa, L. F., Mendes, D. M. L. F., Vieira, M. L. et al. (2012). Self-recognition and self-regulation: the relationship with socialization trajectories and children's sex. Spanish Journal of Psychology, 15(2), 604-612.

Stenberg, C. R., Campos, J. J., \& Emde, R. N. (1983). The facial expression of anger in seven-month-old infants. Child Development, 54, 178-184.

\section{Autores:}

Deise Maria Leal Fernandes Mendes - Doutora em Psicologia Social pela Universidade do Estado do Rio de Janeiro (UERJ), com pós-doutorado em Psicologia do Desenvolvimento pela UERJ. Professor Adjunto do Instituto de Psicologia, Universidade do Estado do Rio de Janeiro.

Lilia Iêda Chaves Cavalcante - Doutora em Psicologia pela Universidade Federal do Pará. Professor da Faculdade de Serviço Social Universidade Federal do Pará e Docente do Programa de Pós-Graduação em Teoria e Pesquisa do Comportamento.

Endereço para correspondência:

Deise Maria Leal Fernandes Mendes

Rua Edwaldo de Vasconcellos 20/302

CEP: 22795-385 Rio de Janeiro, RJ, Brasil

Tel.: (21)2437-9871

E-mail: deisefmendes@gmail.com

Recebido em: 25.10.2013.

Aceito em: 08.01.2014, 